
or not receiving renal suppor treatment by age group

\begin{tabular}{ccc}
\hline Age group & $\begin{array}{c}\text { Treated } \\
(\mathrm{n}=107)\end{array}$ & $\begin{array}{c}\text { Untreated } \\
(\mathrm{n}=57)\end{array}$ \\
\hline $25-$ & 5 & 2 \\
$30-$ & 7 & \\
$35-$ & 13 & 3 \\
$40-$ & 11 & 2 \\
$45-$ & 18 & 5 \\
$50-$ & 10 & 5 \\
$55-$ & 8 & 18 \\
$60-$ & 16 & 16 \\
$65-$ & 6 & 16 \\
$70-$ & 3 & 16 \\
$75-$ & 3 & 9 \\
$80-$ & & 3 \\
$85-$ & & 5
\end{tabular}

Joint Academic

Department of General

Practice and Primary Care, Medical Colleges of

St Bartholomew's and the

London Hospitals, London

Lesley Southgate, FRCGP,

senior lecturer

Sub-Department of

Virology, Institute of

Ophthalmology, London

John Treharne, PHD, reader

Department of Medical

Microbiology, The London

Hospital Medical College,

London

Rosamund Williams, PHD,

senior lecturer

Correspondence to:

Dr Lesley Southgate, Joint

Academic Department of

General Practice and

Primary Care, New Science

Block, Charterhouse

Square, London

EC1M 6BQ

BrMed f 1989;299:1136-7 plantation or dialysis, even though the survival rate is $10-15 \%$ shorter than that in non-diabetic subjects. These results represent a considerable advance. ${ }^{4}$ Until recently most diabetic patients developing renal failure were denied renal support treatment, and even as recently as 1982 only 106 patients in the United Kingdom started such treatment. ${ }^{5}$

The survey in 1985 identified 181 diabetic patients with advanced, previously untreated renal failure in six of the $18^{\circ}$ health regions in the United Kingdom. We followed the outcome in 176, of whom most (93\%) had either died or started renal replacement treatment before the end of 1986. Nearly two thirds of the patients (107) received treatment, usually continuous ambulatory peritoneal dialysis. This is a considerable advance on the figures in previous years. Extrapolation of these figures to the whole of the country is obtained by multiplying by approximately three. There was a clear age bias in selection for renal support treatment; those patients who received dialysis or transplantation were in general younger than those who did not (table).

A third of the patients, however, died without renal support treatment. Some deaths, notably from acute myocardial infarction, were probably unavoidable, and a few patients (10) were over 75 years of age. The rest died from renal failure alone or renal failure complicated by "cardiac failure," which presumably indicated fluid retention. Many of these patients could probably have been successfully treated and fluid retention and "cardiac failure" alleviated if renal support had been given at an appropriately earlier stage of their disease. This neglect should not occur nowadays. In the past many reasons were given for assigning patients as "unsuitable" for renal support treatment"; most of these are no longer valid and only dementia, senility, carcinomatosis, and occasionally multiple overwhelming disorders should lead to exclusion. Blindness alone should not preclude patients from receiving such treatment.

In future diabetic patients with nephropathy should be attended jointly by diabetic and renal physicians working together. Considerable attention must be given at an early stage to the detection and treatment of major vascular disease to pre-empt as far as possible the development of problems during renal support treatment. ${ }^{4}$ All diabetic patients with nephropathy should now be considered for such treatment, which should be started either when fluid retention or other uraemic features develop or when glomerular filtration is usually less than $20 \mathrm{ml} / \mathrm{minute}$ and the serum creatinine concentration greater than $450 \mu \mathrm{mol} / 1$.

We thank the many physicians who helped with this survey and completed two or sometimes three questionnaires.

The working party included Sir Richard Bayliss, Sir Cyri Clarke, and the late Professor A G W Whitfield, Royal College of Physicians; Dr C Brown, Royal Hallamshire Hospital, Sheffield; Professor J S Cameron, Ms Angela Goodwin, Professor H Keen, and Professor G C Viberti (secretary), United Medical and Dental Schools of Guy's and St Thomas's Hospitals, Guy's Hospital; the late Dr J T Ireland, Glasgow; Professor M McGeown, Belfast City Hospital; and Dr P J Watkins (chairman), King's College Hospital, London.

1 Borch-Johnsen K, Andersen PK, Deckert T. The effect of proteinuria on relative mortality in type 1 (insulin-dependent) diabetes mellitus. on relative mortality in

2 Drury PL, Watkins PJ, Viberti GC, Walker JD. Diabetic nephropathy. BrMed Bull 1989;45:127-47.

3 Joint Working Party. Renal failure in diabetics in the United Kingdom deficient provision of care in 1985. Diabetic Med 1988;5:79-84.

4 Goetz FC, Elick B, Fryd D, Sutherland DER. Renal transplantation in diabetes. Clinics in Endocrinology and Metabolism 1986;14:807-21.

5 Cameron JS, Challah S. Treatment of end-stage renal failure due to diabetes in the United Kingdom 1975-1984. Lancet 1986;ii:962-6.

(Accepted 15 August 1989)

\section{Detection, treatment, and follow up of women with Chlamydia trachomatis infection seeking abortion in inner city general practices}

\author{
Lesley Southgate, John Treharne, \\ Rosamund Williams
}

Many women who seek an abortion consult their general practitioner, but specimens are rarely taken to exclude genital infection. Nor are such tests performed routinely in clinics that arrange abortions, and few patients are followed up. ${ }^{1}$ In women who have gonococcal or chlamydial cervicitis an abortion is associated with an increased risk of infection of the upper genital tract and subsequent tubal damage, infertility, and ectopic pregnancy. ${ }^{23}$ Prophylactic antibiotic treatment for women at termination has been recommended, but optimum care requires the identification, treatment, and follow up of infection and treatment of partners to avoid reinfection. ${ }^{+}$

The aim of this study was to identify, treat, and follow up all women with chlamydial cervicitis in the group requesting a termination of pregnancy in four neighbouring inner city practices during one year.

\section{Patients, methods, and results}

Consecutive women requesting an abortion between 1 September 1986 and 1 September 1987 were offered preabortion screening for infection. Demographic data and genitourinary symptoms, either volunteered or elicited, were recorded and each woman examined according to a standard protocol. Specimens for bacteriological examination were collected from the cervical os and the posterior fornix on propax foam swabs (Smith and Nephew). Specimens for detecting Chlamydia trachomatis were taken from the endocervix using dry, cotton tipped swabs and examined using the Microtrak test (Syva) performed according to the manufacturer's instructions. ${ }^{5}$ All slides were examined by JT. Specimens were considered positive if 10 or more chlamydial elementary bodies were detected per smear. Women infected with $C$ trachomatis were treated (see figure), advised that their partners should seek treatment, and urged to return for follow up.

Of the 8002 women aged 16-45 registered during the study year, 120 requested referral for abortion. The age specific rates for women aged 16-24, 25-34, and $35-44$ years were 22,18 , and 3 per 1000 respectively. Altogether, 103 women were recruited to the study, 12 of whom had chlamydia infection but no symptoms or clinical signs. The figure shows the outcomes for the women.

A total of 96 women had a termination, of whom nine consulted within three weeks for serious problems connected with the abortion. Five of the nine had an infection of the upper genital tract and four were readmitted with retained products of conception. All the women treated for chlamydial cervicitis remained symptomless. Eight were negative at follow up and three who were in good health refused follow up tests. None of the five women with upper genital tract infection had received antibiotics before the abortion. 


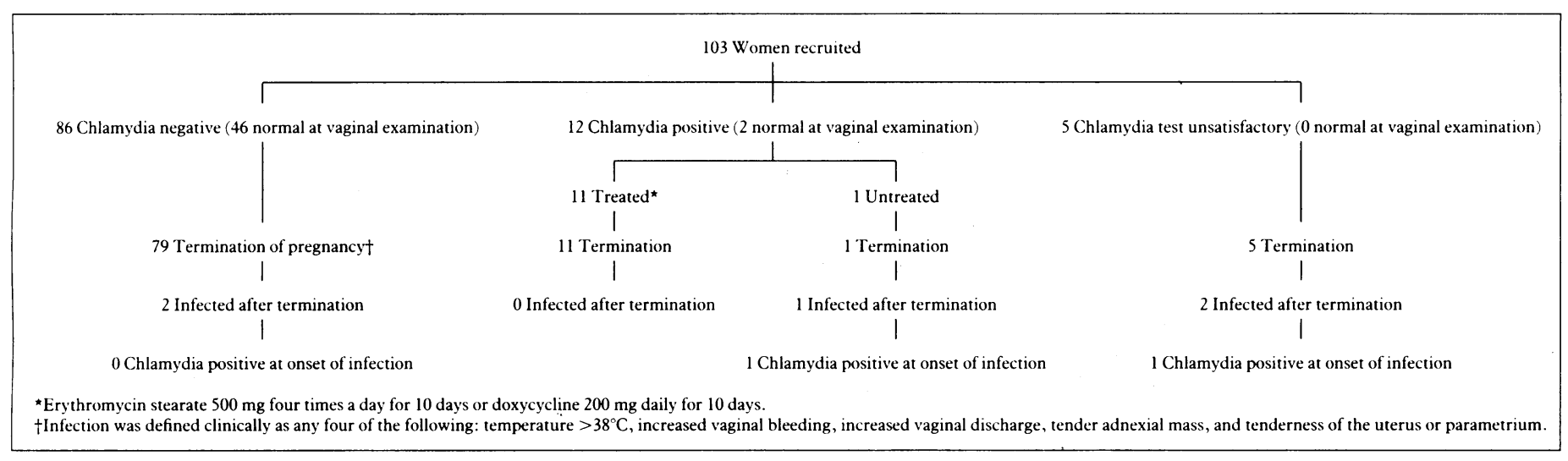

Detection, treatment, and follow up of women requesting termination of pregnancy

\section{Comment}

Most of the women seeking abortions in the practices were healthy and remained so afterwards. The most common complication was infection of the upper genital tract in five women. Two women presented with a severe, acute illness within 48 hours of termination, and $C$ trachomatis was implicated in both. The results of bacteriological studies of both women before termination showed no other organisms such as Mycoplasma hominis or anaerobes, which are commonly associated with infection after an abortion. Ensuring that the women were free of chlamydial infection before the operation would have avoided complications afterwards.

Women living in inner cities who seek an abortion are at high risk of infection with chlamydia. As clinical features are unreliable in identifying women at risk, we conclude that all of these women should be tested and treated before operation and that tests should be repeated before termination if results are initially unsatisfactory.

1 Duthrie SJ, Hobson D, Tait IA, et al. Morbidity after termination of pregnancy in first trimester. Genitourin Med 1987;63:182-7.

2 Barbacci M. Post abortal endometritis and the isolation of Chlamydia tracci $M$. Post abortal endometritis and

3 Heisterberg L, Hebjorn S, Andersen LF, Petersen $\mathrm{H}$. Sequelae of induced first-trimester abortion. Am f Obstet Gynecol 1986;155:76-9.

4 McGregor JA. Prophylactic antibiotics unjustified for unselected abortion patients. Am f Obstet Gynecol 1985;152:722-3.

5 Longhurst HJ, Flower N, Thomas BJ, et al. A simple method for the detection of Chlamydia trachomatis infections in general practice. $f$ R Coll Gen Pract 1987;37:255-6

(Accepted 2 August 1989)

\section{Acute renal failure after infusion of gelatins}

\section{S F Hussain, P J T Drew}

Wrexham Maelor Hospital, Wrexham, Clwyd LL13 7TD

S F Hussain, MRCP, medical registrar

P J T Drew, MD, consultant physician

Correspondence to: Dr Drew.

BrMed f 1989;299:1137-8 permanent renal failure.

\section{Case report}

Gelatin solutions are widely used as plasma substitutes. Although most gelatins are excreted by the kidneys, studies have suggested that they are not nephrotoxic.' Gelofusine (Consolidated Chemicals, Wrexham) is a commercial preparation of gelatins of varying molecular weights. We report a case in which infusion of Gelofusine was implicated in the development of

A 67 year old man underwent aortobifemoral grafting for severe atheromatous disease of the iliac vessels. Before operation analysis of urine yielded normal results and serum urea, electrolyte, and albumin concentrations were normal. He received alfentanil and thiopentone as anaesthetic agents and atracurium for muscle relaxation, and his blood pressure was well maintained throughout the operation. Blood loss was minimal, but urine output fell during the operation. To maintain a slightly raised central venous pressure he was given a total of three units of blood and two litres of Gelofusine during the 48 hours after induction of anaesthesia as well as mannitol $(330 \mathrm{ml})$, frusemide (20 $\mathrm{mg}$ four times daily), and infusion of dopamine at a low dose.

Despite these measures he developed oliguric renal failure: daily urine output in the first three days after the operation was $1307 \mathrm{ml}, 960 \mathrm{ml}$, and $315 \mathrm{ml}$ respectively. Plasma creatinine concentrations had risen to $550 \mu \mathrm{mol} / 1$ by the third postoperative day; at this stage his serum albumin concentration had fallen to $16 \mathrm{~g} / \mathrm{l}$, although plasma oncotic pressure was within the normal range. Microscopic examination of urine showed broad granular casts typical of acute tubular necrosis. He received haemodialysis for six weeks but failed to have a diuresis. An arteriogram showed that the renal arteries were widely patent, and renal biopsy showed normal glomeruli but severe tubular damage. Two years later he was receiving continuous ambulatory peritoneal dialysis.

\section{Comment}

This patient's acute renal failure developed after an operation on the aorta, infusion of Gelofusine, and considerable changes in the serum albumin concentration. We cannot exclude the possibility that the renal failure was secondary to a transient reduction in renal perfusion pressure; indeed, this may be the explanation for the fall in urine output during the operation that led to the infusion of the Gelofusine. Nevertheless, the changes in the serum albumin concentration despite a normal plasma oncotic pressure suggest that Gelofusine accumulated in this patient and that it is potentially nephrotoxic.

There are many similarities between Gelofusine and the dextran solutions, which are well recognised causes of renal failure. ${ }^{2}$ Both types of solutions are made up of molecules of varying sizes that are largely filtered by the kidneys and will precipitate when concentrated, and both solutions are hyperoncotic compared with plasma. The nephrotoxicity of dextran solutions probably depends on the presence of additional factors such as reduced renal perfusion pressure and diminished rates of urine flow, both of which favour the 